\title{
Business Librarians Exchanging Instructional Materials (BLExIM)
}

\author{
ANNETTE BUCKLEY \\ orcid.org/0000-0001-6258-8282 \\ University of California Irvine, Irvine, CA \\ annetteb@uci.edu \\ KARA VAN ABEL \\ University of Alabama at Birmingham, Birmingham, AL \\ kvanabel@uab.edu
}

\begin{abstract}
This article provides a brief overview of BLExIM, which is both a process and finding aid for business librarians to share the instructional materials (IM) that they have created, and receive IM created by other business librarians. We discuss the background of BLExIM's development and functionality, we summarize our promotions to date, and we address concerns that business librarians may have about using BLEXIM.
\end{abstract}

Keywords instructional materials; teaching; reference

\section{History}

From late May into June of 2020, Annette Buckley, the Business and Economics Librarian at UC Irvine, started brainstorming ways to offer more asynchronous information literacy and business research instruction in response to the COVID-19 lockdown. Rather than reinventing the wheel and producing instructional materials (IM) from scratch, Buckley wanted to find a way for business librarians to systematically and widely share the IM that they had already created.

First, Buckley reached out to Kara Van Abel, the Business Librarian at the University of Alabama, Birmingham, who is well-known for her Business Research Toolkit. The Business Research Toolkit is an intensive seven-week program that teaches advanced business research skills across many topics using a variety of online databases and websites. It is open to all UAB students, faculty, and staff, though its primary audience is graduate students.

Then during a June 5th social hour for members of BRASS (Business Reference and Services Section, a subdivision of the American Library Association), several business librarians voiced similar desires for sharing instructional materials, and Orolando Duffus, the Business Librarian at the University of Houston was especially interested.

Throughout July and August of 2020, the three co-creators (hereafter "we" or "us") met virtually for eight hours of intensive discussion, debate, and collaboration, to create the beta version of BLEXIM (http://sites.google.com/view/blexim-sharing). To summarize, BLExIM affords business librarians the opportunity to share instructional materials that they created and to discover, receive, and adapt materials that others have shared. 
Ticker: The Academic Business Librarianship Review, 6:2 (2021)

https://doi.org/10.3998/ticker.1942

(c)2021 Annette Buckley and Kara Van Abel

\section{Building BLExIM}

Figuring out the logistics of BLExIM required significant mental gymnastics for us. First, we decided that the most efficient way to manage BLEXIM was through a single Google account for which all three of us shared the login credentials. Second, we debated what gets shared; the IM has to be editable so receivers can modify the IM as desired (e.g., the script of a video lecture rather than a recorded video lecture). Third, we determined reasonable workflows for business librarians who would be sharing, searching for, and receiving IM. Fourth, we tested and refined the sharing and receiving workflows. Finally, we packaged the whole BLExIM system into a Google website, in order to market and teach it to our colleagues.

The key components of the BLEXIM website are:

- an overview of what BLExIM entails;

- instructions about how to share or receive IM;

- a registry, i.e., a finding aid, of the IM that business librarians have shared through BLExIM, enabling people to receive IM; and

- an input form for sharers to use to easily populate the registry.

All IM shared on BLEXIM is done so with the understanding that participants adhere to the CC BY-NC license. In summary, people may redistribute and transform material, so long as they attribute the original creator, and they do not use the material for commercial purposes (Creative Commons, n.d.). Also, it is worth noting that, "[BLEXIM] does not host IM, and the [co-creators] do not curate or police Sharers' content. What we've created is a discovery tool for IM, i.e. the BLExIM Registry, as well as a standard workflow for exchanging IM" (Business Librarians Exchanging Instructional Materials, n.d.).

To understand the workflow, here we describe a real-world scenario. Using the Canvas platform, Van Abel has created a robust piece of IM called the Business Research Toolkit (BRT), and she is willing to share the BRT with other business librarians. She put the BRT Canvas course files in a publicly accessible folder on her Google Drive. She then populated the BLExIM Registry with basic descriptive information about the BRT, including a link for downloading the complete Canvas course files. Subsequently any business librarian may receive the BRT that Van Abel shared and adapt it for their own population(s). Before a receiver downloads the BRT file, we ask them to complete Van Abel's Notice of Use (NoU) form. Van Abel would see who completed her NoU, so she could gauge the wider impact that her IM is making.

We devised the NoU form to serve two purposes. First, it helps with attribution. If Buckley at UC Irvine receives Van Abel's IM and adapts it for the UC Irvine audience, then attribution could be somewhat impractical (e.g., Buckley adapts three questions from the BRT for her own 10-question Canvas course). With the NoU, Van Abel knows that Buckley may be adapting the BRT for UC Irvine. Second, it acts as an incentive for sharers, i.e., they receive positive feedback from receivers when they complete the NoU. Furthermore, this NoU feedback may be especially important for those business librarians who go through merit reviews.

Lastly, we encourage sharers to post updated versions of their IM as applicable through an easy process. If Van Abel updates the BRT, she would simply replace the old BRT files in her Google Drive folder with new ones. She would not need to make any changes to the entry in the BLExIM Registry, because the registry only links to her Google Drive folder, not the IM files within the folder. 
Ticker: The Academic Business Librarianship Review, 6:2 (2021)

https://doi.org/10.3998/ticker.1942

(c)2021 Annette Buckley and Kara Van Abel

\section{Launch \& Promotion}

The Beta version of BLEXIM was released in August 2020. We made announcements via business librarian listservs and in a BRASS Discussion Group virtual meeting; however, the academic year had already started, and we found that submissions were limited.

In February 2021, representatives of the BLA (Business Librarians Association), based in the United Kingdom, contacted us to say that they were inspired by BLEXIM and were considering emulating it for their membership. We walked them through BLExIM, and BLA gave excellent feedback, which we used to improve the sharing/receiving instructions.

Also in February 2021, business librarians in the Academic Business Library Directors (ABLD) invited Buckley, an ABLD member, to present on BLExIM during the March 2021 Annual Meeting, held virtually.

In May 2021, we hosted BLExIM Week, a four-day event to encourage awareness of the resource and support users who want to share or receive IM. The event included a day of asynchronous participation where participants were encouraged to view teasers of available IM in BLExIM, a day with a live presentation walking participants through how the process works, and two consecutive days of a share-and-receive-a-thon where participants could drop-in and interact with BLExIM while we were there to answer any questions.

\section{Looking Forward}

Despite our efforts to promote the new resource, the BLExIM registry is still quite small, and the project continues to be a work-in-progress. We perceive a need, but we detect hesitancy from librarians to participate. Below are the concerns that we have identified and our responses addressing each concern:

- Is it legal for me to share IM that I created?

Although there is some debate on this subject, the short answer is yes. Historically, college professors and those working in academia retain the copyright for instructional materials they have created (Flaherty, 2020).

- Is my IM "good enough" to share with my colleagues?

Yes! We encourage business librarians to share their IM with confidence. You created your IM for a reason, so the odds are that another business librarian will face a similar need at their institution. You may think your IM is rudimentary, but for a colleague, it could be an elegant solution, from a fresh perspective. IM does not need to be perfect to be useful.

- Do I have the time to share/receive IM?

\section{Sharers}

If you know what IM you want to share, then you should plan on the initial setup taking approximate 30 minutes (making a shared folder in a Google Drive, populating it with IM, customizing the NoU form, and adding information about your IM to the BLExIM Registry). After you complete the initial setup, sharing future (or updated) IM takes about five minutes per entry. 
Ticker: The Academic Business Librarianship Review, 6:2 (2021)

https://doi.org/10.3998/ticker.1942

(c)2021 Annette Buckley and Kara Van Abel

\section{Receivers}

It might take seconds to brainstorm an idea (e.g., a presentation on market research) but hours to execute and package that idea into IM. Browsing the BLExIM Registry for existing IM could save you those hours reinventing the wheel.

- I haven't shared any IM. Is it OK for me to receive IM before sharing?

Of course! BLExIM was created with the intention of connecting business librarians to IM when they need it. There's no reason to hesitate if you find materials you can adapt. Sharing IM is more time-consuming than receiving IM, and you should wait until you are ready to take that step. Also remember that by completing a colleague's NoU form, you are providing them with valuable feedback about the potential wide-ranging impact of their work.

BLEXIM needs input to gain momentum, so we implore all business librarians to participate by either sharing or receiving instructional materials! 
Ticker: The Academic Business Librarianship Review, 6:2 (2021)

https://doi.org/10.3998/ticker.1942

(c)2021 Annette Buckley and Kara Van Abel

\section{References}

Business Librarians Exchanging Instructional Materials (BLExIM). (n.d.). Home.

https://sites.google.com/view/blexim-sharing/home

Creative Commons. (n.d.). Attribution-NonCommercial 4.0 International (CC BY-NC 4.0). https://creativecommons.org/licenses/by-nc/4.0/

Flaherty, C. (2020, May 19). Who owns all that course content you're putting online? Inside

Higher Ed. https://www.insidehighered.com/news/2020/05/19/who-owns-all-course-content-youre-puttingonline 